\title{
Encouraging Socio-Ethnic Pluralism in Arab High Schools in Israel: Perspective of the Headmasters and Educational Staff
}

\author{
Muhammad Suwaed ${ }^{1}$ \\ ${ }^{1}$ Department of Political and Social Sciences, Western Galilee and Kinneret College, Israel \\ Correspondence: Muhammad Suwaed, P.O.B. 73, 30055 Rama, Israel. Tel: 972-507-362-425. E-mail: \\ suwaedm@hotmail.com
}

Received: February 7, 2014 Accepted: March 10, 2014 Online Published: March 27, 2014

doi:10.5539/ies.v7n4p86

URL: http://dx.doi.org/10.5539/ies.v7n4p86

\begin{abstract}
The paper presents the perspective of headmasters and educational staff un a sample of Arab high schools in Galilee, Israel, employing and serving a mixed population comprising Moslem and Christian communities.. The paper describes efforts made by these schools to bring people closer, and examines programs designed for this purpose, and factors involved in these attempts. It also presents and discusses the role of school headmasters and leading staff, their contribution to the cause, and focused on their points of disagreements and their proposals regarding ways to improve the existing situation and promote social pluralism among students. The paper also presents, approaches prevailing in the Ministry of Education and local authorities, and examines educational programs designed by external and internal bodies, and other educational initiatives adopted by the participating schools, to increase tolerance and respect among students. In addition, the paper analyses, goal-directed educational programs proposed and implemented by school headmasters and leading staff, lessons that could be drawn from these exercises and their implementation, and the headmaster's social status and influence in advancing social changes in the given community. The findings showed significant differences in the perception of situation between majority and minority community representatives in each given village. Furthermore, they clearly indicated that the students were not adequately exposed to each other's cultures and were significantly influenced by incorrect perceptions and superficial/erroneous interpretations. Thus, it was recommended to introduce intervention programs based on respect for difference, renunciation of enforced uniformity, promotion of maximal freedom of choice in the way of life, and dialog between different cultures.
\end{abstract}

Keywords: Christian, Moslem, Arabs, high school, pluralism, multiculturalism, ethnicity

\section{Introduction}

Over the past two decades, regrettable violent events in some Arabic towns and villages with mixed population of Moslem, Christian, and Druze communities in the Galilee had occurred. These events led to discord and clashes among the communities. Although these regrettable events had not recurred, the fear of a future outbreak motivated religious, social, and educational sectors to seek insights that could lead to tolerant and mutual respect of people coexisting in mixed residential locations. Socio-conceptual change begins with education as the main factor, affecting and forming values, behaviors, beliefs, and perceptions of the future generation. Education starts at home, and is influenced by all the aspects of the parents' and society's worldview. When children enter the official educational system, their exposure to a different set of rules, a larger framework, and their peers in school take a central role in shaping their worldview. Therefore, the official educational system can be used as a major agent for changing social approach.

In this pilot study, the data, conclusions, and recommendations drawn from the findings had been presented after examining the impact of educational institutions on the social climate in Arab towns and villages with mixed population in Galilee. Social aspects of interrelations involving Druze and Bedouin communities were excluded, since these two communities are closer to the Jewish majority of Israel; a closeness that bears upon the individual and community sense of identity, and their perception of other groups within the intricate nature of Israeli society. The study focused on clashes that occurred in Arab towns and villages in which Moslems and Christians live side by side. It tried to identify ways that could lead to intercommunity dialog among social, religious, and educational leaders, which could be applied to local educational programs to bridge cultural gaps, bring mutual tolerance, and reduce violence. Based on the findings obtained, the study recommends introduction 
of social and educational programs directed toward pluralism, multicultural worldview, and respect for and acceptance of others. Although it is a language of a national minority, Arabic is the second official language in Israel. Thus, Arabic-speaking pupils attend separate schools that belong to a separate educational system geared to Arabic speaking population, However, this educational system is subdivided: it provides separate schools for Druze pupils and certain parts of the country, there are also separate schools for Bedouin pupils. There are 175 high schools in northern Israel that cater for Arabic speaking pupils of all kinds, (Khamaisi, 2011, p. 191), but only 36 of them serve mixed population of Moslem and Christian pupils (Ministry of Ed site) Not all the schools approached by the researcher wanted to participate in the study, and those that agreed to do so insisted on the confidentiality. Thus, the study was conducted in a sample of five Arabic high schools in Galilee, subject to pre-agreed terms. The sample, comprising about $17.5 \%$ of the target high schools includes schools that experienced violent events.

The researcher was attentive and gained the participants' cooperation and trust by agreeing to their terms not to disclose the names of locations, schools, and participants. Accordingly, the participants were indicated only by their respective subgroup affiliations, and their roles and functions were as follows:

(1) a. religious, b. social, and c. educational.

(2) a. authority, religious leader, and spiritual leader; b. municipal authority, parents, welfare bodies, and police bodies; and c. headmaster, professional teacher, psychologist, educational counselor, and social coordinator.

A comprehensive literature survey was conducted prior to the study, but as it was found, most of the studies available in the field dealt with educational policies in countries where national and cultural minorities are required to learn and use the dominant majority's language to integrate professionally, socially, and politically, rather than issues within a given minority.

The popular trend in Israel and the European Union is to link education with peace and pluralism. The available literature deals with various approaches encouraging mutual respect and tolerance toward others. As this is a pilot study concerned with animosity among subgroups within a national minority, the researcher's search for relevant literature was futile. All the available studies (in Hebrew, Arabic, and English) deals with the fact that state policy is generally tuned toward the culture of its majority and its efforts and consideration (or lack of it) toward the minority culture. Several studies and articles discussed the attitude of immigrants to their original culture and traditions, which they brought to the host country. The literature survey (Lam, 1996; Shavit, 2002; Smooha, 1987; Suan, 2000; Yaakobson, 2012; Yona \& Shenhav, 2000) revealed that during the entire history of the State of Israel, various policy manifestos, studies, and recommendations regarding intercommunal and intercultural educational programs have been published. However, all of them dealt with government policies, representing the Hebrew-speaking majority culture, toward the Arabic-speaking minority and their culture. Nevertheless, the researcher found some models developed in other countries that were applicable/partially applicable to the present study's goal in bringing tolerance and mutual respect for others by creating mutual understanding among different cultural groups.

Cultural pluralism can be taught in school and reinforced in the surrounding framework in which the process occurs. A pluralistic policy is based on numerous models. For example, multiculturalism can be based on demographic structure of an entity in which different ethnic and cultural groups live together (Reingold, 2005; Sever, 2001; Shenhav-Keller, 2010; Tamir, 1998). Multiculturalism can also be built on structural aspect when the government enables and promotes an honest and egalitarian division of the state's resources (Mickelson, 2001; Sever \& Gur, 2001; Zolberg, 1996). Peace is a social state reflected in mutual recognition, mutual respect, and willingness for cooperation among diverse social groups, despite and owing to their differences, in an effort to prevent the curtailment of the basic rights of some of them.

Educational policy also has an ideological aspect; thinkers and researchers in this field (Bodu, 1996; Mautner, Sagi, \& Shamir, 1998; Yona, 1998) claim that a multicultural society can be defined as such only if it treats all its members with respect and is committed to cultural heterogeneity. Therefore, to create mutual respect among various cultures, a multicultural educational policy should be promoted and multicultural education models should be adopted as a substitute for assimilatory, ethnocentric education.

Yogev (2001) distinguishes between a pluralistic approach (demanding moral education in multiculturalism, with the intention of developing students' knowledge and empathy toward each other) and the willingness to accept others. Furthermore, adoption of a differential/particular approach was also suggested, whereby each group is invited to express its cultural uniqueness and values in a separate educational framework, to break the power structure and social control mechanisms. In the former approach, all the students learn about themselves and others in the group, and in the latter, every group learns about itself and expresses this understanding to 
others. In the present study, the practice of each participating school was examined according to the perceptions of the school headmaster and leading staff. The framework of this study also included analysis of programs designed and distributed by the Ministry of Education, local municipality, and those developed by other parties such as religious council/spiritual leaders and local social leaders..

\section{Background}

Israeli society is composed of communities and groups characterized by different values, customs, and symbols. According to Ganem (1990), the Israeli society is an intricate ethnic cultural and national patchwork, containing greater and deeper differences than commonalities. Thus it always suffers from cognitive dissonance. Arabs constitute $20 \%$ of the Israeli population, (CBS, 2014; Khamaisi, 2011, p. 88-99) but they are also divided into subgroup practicing different cultures such as Moslems, Christians, Druze, and few smaller groups.

The Moslem community is the largest minority group, comprising $80 \%$ of all the minorities in Israel. They are further divided into secondary subgroups, each of which has different ethnic/cultural characteristics. The major groups are rural (fellahin) Arabs, urban Arabs, and Bedouins, small esoteric groups including Ahmedis and Bahais, and Moslems of different ethnic origins such as Circassians and Sudanese (Stendal, 1992; Suwaed, 2004). Except for the Cicassians, all these groups share the Arabic language and its cultural derivations, and stem from the Sunni faction of Islam. In the past, the dominant group in the Moslem community was the fellahin. However, this changed because of the downgrading of agriculture from its central role in society and development of industry, technology and other aspects of modernism, along with the increase in educational attainment levels, leading to a significant growth in the number of professionals. Since the establishment of the State of Israel, there has been a noteworthy increase in the status and achievements of urban Arabs.

To date, the Arabic speaking Christian community in Israel comprises about 160,000 people, constituting $12 \%$ of the state's minorities. Although some Christian Arabs live in rural areas, most Christians Arabs belong to an urban society, and are divided into subgroups according to church affiliation: Greek Orthodox, Catholic, Maronites, and several smaller factions of Protestant conviction (Tzimhoni, 1999).

The Druze community is a uniform society comprising of about 130,000 people. For historical reasons, Druze has a status different from other Arabic-speaking minorities in Israel, and their children attend schools designed to serve this specific community. The entire Druze community and most of the Christian Arabs live in Northern Israel. A significant number of Christian pupils (particularly those from urban communities) attend private schools run by their churches.

However, in rural areas, the circumstances are different. Children who live in a mono-religious village/town attend a mono-religious school, where they are not exposed to ethnic/religious tension; where children living in a mixed-population village/town and attend a regional school serving a number of small villages meet pupils from different cultural backgrounds. This encounter can be positive because the children have an opportunity to meet and mingle with others, but it can also be negative, especially when external disputes are echoed in school.

Arab education in Israel reflects the internal struggles taking place in this society: tradition versus modernism, Israeli versus Palestinian, and secular versus religious. Furthermore, this society endures internal quarrels and struggles where conflicts are often linked to faith. In the past, the Arab society was characterized by a traditional religious quality; there were neither absolute secularists nor fundamentalists. All of them lived in relative peace in a consensual traditional lifestyle. However, over the last decades, the conditions have changed owing to advances in media and communication technology. Global and regional unrest, cultural disputes, and coverage of conflicts among different elements of the Israeli society now reach every household. Discrimination on religious grounds implies a different attitude toward others based on religious convictions. A chain of local and regional events in recent decades affected the Arab society in Israel, resulting in regrettable violent incidents in various mixed-population towns and villages.

As educational system is a social institution influencing attitudes, behavioral patterns, and recognition of other persons, it plays a significant role in bringing cultural and social changes, influencing the stratified structure in Israeli society, including the Arab society (Yogev, 2001). Children of the Israeli Arab minority group attend schools in which the medium of instruction, including the study materials, is Arabic. In large towns where the minority population is diverse, students have a choice of schools. Pupils from the Moslem community usually attend state educational institutions, while a significant percentage of the Christian pupils attend schools run by various churches/schools of the Alliance network, under the auspices of the French Ministry of Culture (El-Haj, 1996).

Most of the pluralistic education models practiced worldwide and in Israel, and majority of the literature, deal 
with the need for the dominant majority in the state to recognize and respect the cultural values/ethnic uniqueness of minority groups. In the light of past events, there is a need to not only recognize the minorities living in Israel, but also that they are not a uniform group. Moreover, attention and resources should be provided to encourage tolerance, mutual respect, and willingness for cross-communal cooperation among minorities. It should also be noted that in Israel, most of the minority citizens live in towns and villages where there is no Jewish population. Thus, the dominant majority culture in the state does not significantly influence their sense of identity and is not directly involved in the intra-communal relationship in those places. Therefore, in this context, theories regarding cultural pluralism and its implementation do not depend on official/government policy, because the relationship among different communities is a consequence of a contemporary population composition and past memories. The goal of the present study was to investigate this subject from a micro-perspective to find applicable ways to encourage tolerance, acceptance of others, and mutual respect, which would fit the needs of every educational institution.

\section{Method}

This study was conducted in five state high schools serving minority populations, located in towns with diverse minority communities. The participating schools were chosen from the list of schools attended by Christian and Moslem pupils, and the teaching staff represented both the communities residing in the given town/village. Two of the ample schools are located in towns that endured violent disputes between the communities. One of them in a town with a Moslem majority and the other is the sole high school in a small town/large village where Christians are the majority. The other schools included one in a village, which underwent violent events that were not sparked by ethnic differences and is trying to rebuild and recuperate, a high school located in a town with a small Christian minority, $(10 \%)$, which was never persecuted/oppressed; and a school in a village where Christians live in a separate neighborhood near the Moslem residential area for generations, enjoying peaceful bilateral relations and mutual respect. The study included educators fulfilling the following roles: school headmasters, educational counselors, social education coordinators, and a representative model of teachers and educators from both the communities, teaching in mixed-population classes.

The study was conducted using a qualitative approach. The main research tool employed was a semi-structured interview. The questionnaire was designed by the researcher, who modeled it according to a pre-existing format with subcategories as per the interviewees' respective roles. After the structured part, the interview continued in an open informal discourse. This second part was an interactive session, enabling the interviewee to tell and re-examine some personal stories. To obtain the data required, the researcher refocused the discourse on the following questions:

(1) Are intervention programs for the advancement of peace and pluralism run in the school? What programs are adopted and used by the school, and who administers them? What impact do they have on the relationships among students of different communities?

(2) What is the influence of external relations between the communities in the village/town on the relations among students?

(3) What are the positions of the headmaster and leading staff on the issue, in general, and on the problems that may arise in the village/town where the school is located, in particular?

\subsection{Research Sample and Participants' Characteristics}

At the end of February 2011, the researcher contacted the participant school headmasters who met the study's criterion to obtain their approval and cooperation. After explaining the study aims, the terms were agreed upon, and the technical stages of the study were designed. Owing to the immense sensitivity of this topic in the entire Arab society in Galilee, the researcher and the schools' management agreed upon utmost confidentiality to enable the respondents to consent willingly and speak freely and openly in the planned interviews. The headmasters and the researcher jointly formulated certain cautionary procedures to ensure participants' full anonymity. The study included the following: five headmasters, five educational counselors, five pedagogic coordinators, and ten educators representing the subject matter communities.

The first meeting in every school was conducted with the headmaster. During this meeting, a friendly conversation evolved, and the situation report was discussed, along with the background of events from the headmaster's perspective. Then, the headmaster was interviewed according to the pre-designed questionnaire. Subsequently, the headmaster called the other preselected participants at preset intervals, and the interviews took place in a separate room allocated for this purpose. Every interviewee answered the questions, and the researcher held an informal, interactive discourse with him/her on the issue and other concerns that were raised in the 
conversation. The narratives were gathered from the records of personal discourse between the researcher and every interviewee.

Every interview started with the structured part, with questions prepared in advance for the subgroup to which the interviewee belonged. Subsequently, the interview turned into an open discourse covering additional questions, experiences, and personal stories. Several participants had doubts of their own, and some of them offered suggestions that could lead to improvement/expansion of the issues discussed. All the information obtained was documented and transcribed.

Irrelevant information/contents deviating from the subject matter, including emotions, approaches, images, and personal interpretations, were maintained in a separate file, to be ignored or referred to in the summary. Some of the interviewees hit the target precisely and gave justified and relevant answers, which were organized into a continuous narrative and a definite form following the researcher's questions (Elbaz-Lobish, 2001).

\subsection{Limitations}

The Arabs living in Israel have difficulty in coping with the division between Moslems and Christians and the suffering caused by violent events that occurred in recent years. The first limitation was the respondents' anxiety, they were apprehensive of possible negative reactions they may confront when people read their opinions. The respondents also had doubts regarding the true nature of the events and feared possible misinterpretation. Some worried that their participation could ignite needless hostility between the two communities residing in their village. In this context, one should consider the fact that educated people and school headmasters enjoy a special status in the Arab community and they had a justifiable reason to be concerned. Therefore, to obtain full and honest cooperation, complete immunity, with absolute anonymity, were agreed upon; so participants were referred to by their role description, without revealing school's identity and town's location. Confidentiality rule will also apply in case the materials, including respondents' quotations will be published..

The second limitation was the regrettable fact that during the study period, tensions prevailed among the different ethnic groups in two of the villages/towns where the study was conducted. This situation led to biased comments of some interviewees regarding the causal factors of the ensuing conflict. The researcher chose not to voice any opinion of his own during discourse to maintain his academic distance and neutrality.

\section{Findings, Validation, and Verification}

\subsection{General}

The starting point of this study was the lack of uniformity among the schools examined; the differences were observed in the structure, type, and size of the schools in terms of facilities, number of students, and number of classes. Three of the institutions examined were comprehensive schools, which included a junior and senior high school, and the other two were merely senior high schools. Similarly, there was a difference in the aspect of exclusivity; some of the schools were located in a town large enough to maintain more than a single school. In other cases, it was the only high school in the vicinity. Thus, if a student could not integrate for whatever reason, he/she was forced to seek education outside his/her hometown (i.e., travel a considerable distance to school).

Furthermore, there were fundamental differences in the social backgrounds/community relations in the schools' respective locations. There were schools in towns/villages in which the minority felt threatened. Other schools were located in towns where the people of both the communities were aware of the problem and sought a solution. One of the schools was located in a town where good neighborly relations prevailed, with no intercommunal tensions.

\subsubsection{Findings from the Structured Part of the Interview}

All the interviewees agreed that the subject was important and worth investigating. Most of them thought that one should act both within the school and community frameworks to improve the situation. Everybody also concurred that relationships in schools were affected by factors outside the educational framework, such as home, community, and media. Significant differences were found in the perception of the situation between the representatives of the majority and minority groups in any given location. Most of the interviewees noted that students were not adequately exposed to the other community's culture, and many of them were influenced by incorrect perceptions and superficial and erroneous interpretations.

The findings indicated that the proportion of students from the two communities in several schools did not reflect the relative ratio of each community in the given town/village. The schools situated in the towns, where violent events had occurred, lost a segment of minority pupils who felt insecure and shifted to other schools outside the given town/village. 


\subsubsection{Findings from the Open Interview and Personal Narratives}

Following the interview's structured part, personal meeting continued as an open interview, which was conducted as a discourse. Some interviewees reported experiences and added personal stories in a direct context, while others expressed general impressions. The personal stories provided important data, which were added and sorted according to preset categories. The narratives revealed facts and perceptions of a situation, which deviated from the study framework, but were certainly part of the general situation report (see Discussion Section for some of these additional data and also the Conclusions Section).

The open interviews corroborated and added dimensions to the data gathered in the structured part of the interviews by sharpening the threatened minority groups' fear and anxiety during and since the violent events.

The following were the additional data that were not generated by the predesigned research tool, but were obtained in complementary sessions:

(1) Feelings of frustration and helplessness were experienced by those who tried to pacify the situation during the above-mentioned events.

(2) Profound insights were gained by educators regarding the imperative social role of tradition and clan affiliations versus factors such as education, function, and perceived social status.

(3) The respondents reported feelings of deprivation and bias.

(4) Loyalty to home, family, and clan was marked high in the students' scale of values. This sense of being a part of a larger obligatory framework affected their behavior.

(5) Disputes between two families from the same community could destroy the social fabric in a village and lead different groups to integrate/separate.

(6) In many cases, violence occurred as a result of inner political struggles.

The responses and anecdotes shared during the interviews reminded the researcher about certain similar impressions described as "active and constructive" in the study by Ezer, Malat, and Patkin (2004). The researcher found that he had to listen carefully and interpret the stories containing elements of dismantling and restructuring (deconstruction and reconstruction) of meanings. After gathering and classifying all the findings according to categories, the data were sorted out, and data triangulation was performed to verify certain findings to enable differentiation among problems needing to be addressed at local, district, and federal levels.

\subsection{Analysis of Findings}

The findings revealed feelings of frustration and disappointment of several intellectual education workers troubled by the patterns of behavior and social conceptions they had encountered, whose origin they attribute to "old-fashioned" cultural structures of the societies in which they live. Many interviewees criticized the still honored clan-family system prevailing in Arab villages. The "old ways" dictate loyalties and behavioral patterns, guided by values and norms of the tribal-feudal society, affecting attitudes and beliefs and making it difficult for progress-seeking factors to reach the young generation and teach students to internalize the values and morals of a modern democratic society. The findings also indicated that many students do not perceive themselves as independent individuals, but as belonging to a subgroup they are obliged to obey and support.

On the other hand, the study revealed high motivation among most participants to actively change things, accompanied by self-confidence that these can be achieved.. These participants were convinced that they possess the power to influence students' worldview and regard school as the sole factor in the village that can bring about change. The findings also revealed that most of the schools have no special program devoted to the cause, and no teaching hours have been allotted to enable the educators to formally deal with the situation. However, the subject of multicultural pluralism has often been raised with staff initiative in complementary and/or supplementary sessions. In many towns, a master plan exists in dormant stage at the education department office/local authority, while other towns do not even have that.. Furthermore, there were clear differences of opinion among the education workers regarding the dimension and strength of external influences regulating the town's/village's atmosphere. All the interviewees mentioned the word "respect" and need for an educational program emphasizing pluralism based upon democratic and humanistic values. Other respondents stressed the need to build an action program to foster the return of students who left the local school owing to regrettable events.

\section{Discussion}

Analysis of the findings corroborated the existence of problems of different severities in minority towns/villages 
with mixed populations in Galilee. In most cases, the communities involved were aware of the problems and sought ways to improve the situation. Regarding the implementation of a program for tolerance of cultural pluralism proposed by the Ministry of Education, no difference was noted between schools in which violent events had occurred and those located in towns/villages that have not experienced such events.

The study identified a need for enrichment program for cultural pluralism and tolerance toward others within the school framework, which could eventually be expanded to involve the surrounding community, since the findings indicate that school atmosphere is influenced by the general environment predominant in the community. Furthermore, the study reinforced the impression that social norms in minority communities in Israel, especially those residing in rural areas, are still influenced by ancient traditions and customs, making it difficult to improve various aspects of life, including the subject matter. The findings corroborated the conjecture that the source and main catalyst of recent hostilities between the communities was external factors (mostly political) and interventions.

It appeared that spiritual and religious leaders could play a constructive role in pacifying feelings and urges on both sides. In this context, it was suggested that it may be desirable to increase mutual exposure of students to cultures and relevant universal values. One approach was to devise strategies leading to cooperation between the local communities and with neighboring communities.. Moreover, the findings confirmed the pre-study belief that the atmosphere in each school is affected by the leadership style of its head. The headmaster's job description includes shaping the school and its future aims and promoting ethical, moral, and cultural values. Thus, his/her ideas and perspective influence the definition of educational and instructional targets and the function and progress of the school. All the headmasters who participated in this study agreed that cultural pluralism and mutual respect are aims worthy of pursuit. They also confirmed the assumption that till date, no sufficient action/suitable program to improve the existing intercommunal situation were designed for their schools. A home-teacher is responsible for all the educational and social aspects of his/her pupils, and should ensure that academic progress occurs and in-class social cohesiveness and good interrelations exist. He/she is expected to promote social life in class, initiate social activities, and maintain contact with his/her pupils' parents. All the educators who participated in this study noted that the relations in the village reflect conversations and comments pupils hear at home. They spoke about their efforts to introduce social pluralism issues and their attempts to teach values of mutual respect and tolerance.

Koboby (1978) defined a good educator as someone who respects the student unconditionally as a person, not based on his/her achievements and behavior. The educator distinguishes the student's unique identity, reinforces his/her personal potential, and helps in his/her self-realization. Furthermore, Oppenheimer (2006) discussed "reflective multiculturalism," according to which a person should examine oneself, one's culture, and views, before examining those of others.

The counselor, together with school staff, should aim to improve the school's conditions and climate, encourage students to develop according to their capacities in academic studies, social behavior, and emotional growth, and manage exceptional cases according to the need. Masalha (2004) claimed that the widespread multicultural reality in Israel's current educational system demands redeployment of the school counseling system. The counselors must be involved in an ongoing process of professional development to acquire the knowledge and skills to cope with multicultural difficulties and challenges. Dressel, Consoli, Kim, and Atkinson (2007) pointed out the importance of growing awareness among educational counselors of the existence and causes of potential multicultural conflicts with their counselees. An educational counselor can be perceived in a multicultural context in two forms. First, he/she is an active participant in the meeting of cultures, because he/she belongs to one or the other culture and can experience his/her cultural differences with those who consult him/her and seek assistance and guidance. Second, he/she can also be perceived and act as an agent of change, influencing the shaping of cultural meeting. As such, his/her role is to open and manage involvement of various aspects of cultural, ethnic, religious, and political differences at school and bring them out of the hidden and unspoken realm to one that is open and clear.

The social education coordinator is responsible for the social education program in the school, formation of an annual work program and its writing, and matching the social education program with the unique needs of students. He/she also closely supervises the execution of the social education program in the school. According to Picard (2001), in multinational/multiethnic societies, a struggle occurs among different groups regarding the cultural character of the whole society, when one group tries to impose its culture through de-legitimization of the cultures of other groups. The power of qualitative research not only lies in its findings and conclusions, but also in the interaction between the subject defined at the start of the study and the change it undergoes, following the researcher's presence in the field and his/her listening to the interviewee's response (Shkedi, 2003; Shlaski \& 
Alpert, 2007).

In the present study, all the interviewees criticized the dominant clan-family system in Arab society and explained the difficulty in coping with traditions and customs rooted for generations and imparting values and morals to students, which are incompatible with the accepted norms and rules of behavior in their immediate, larger environment. The participants claimed that many students do not consider themselves as independent individuals, but as members of the family, which they have to support. However, strong motivation to change these norms was noticed, together with the belief in their capacity to do so. Furthermore, a need to conduct an internal cultural discourse among staff members was identified. The educational staff of each school should start and develop an open discourse regarding the students' identity, thereby enabling them to seek culturally impartial answers linked to rewarding conscious multicultural practice. Most of the study participants perceived school as the sole important institution in the town/village that has the ability to lead change and promote pluralism, tolerance, and mutual respect among various local communities.

An individual often lives in a multidirectional, multicultural society and can integrate into it without losing his/her identity. Education geared toward cultural pluralism, mutual respect, tolerance, and recognition of the unique value of every person will protect the identity and uniqueness of the individual and his/her group affiliation, even in a varied and mixed society. It is unacceptable that even in 2013, in a modern state, people residing in places for generations still exist under constant threat to their lives and properties, with reluctance to leave the protection of their homes and consider moving to a safer place. There is a dire need to rectify this situation, and every suggestion should be considered, including the design and introduction of a contributive educational program. The present study exposed the depth of the cultural and social issues in places where daily contact among people often leads to altercations owing to misunderstandings and tensions stemming from differences in cultural backgrounds and perceptions. The researcher's impression was that the communities involved are ready to cope with difficult questions regarding cultural identity, tolerance, and respect for others to retrieve peaceful co-existence for their mutual benefit.

Although questions and doubts were raised confidentially in private conversations, publication of the research findings, might lead people from the communities involved to, voice their opinions and concerns, discuss possibilities and support the efforts to bring change. Cohesiveness among the population components is a necessary condition to achieve multiculturalism and pluralism across classes, whose immediate results are fostering empowerment of students through their unique identities. According to Diab (2002), “...change is a natural product of the dynamics and the meeting with others and it expresses motion over a continuum," or as defined by Bostin (2004), change is growth and expansion.

\section{Summary and Conclusions}

\subsection{Summary}

The school is a social organization, a sort of microcosmic culture with a social structure and local culture. Yet, every school, and every other organization, has norms, behavior patterns, and culture, including symbols and way of life existing in a social structure operating according to the rules and laws applicable to every social framework. An educational system can be examined at every level of its affairs. The examination can be broad and comprehensive or individual and focused, depending on the goals and aims of the study, interested body, parties affected by its results, and any other interested sectors. The goal of education is to equip pupils with personal and behavioral tools that will guide/assist them to integrate into society in the best possible way. The educational system is a structured means designed for the preparation of the future generation in a ranked and rational form adapted to age and capacities, and is expected to provide knowledge and contribute to the enhancement and strength of democracy. An educational institution includes a built-in framework to enable and facilitate desired social processes in which the pupils acquire social skills, as well as learn and assimilate the norms of society, its lifestyle, and cultural and moral heritage.

According to Arieli (1995), the school is a structured educational organization with patterns of authority and decision-making procedures. Recently, the outputs of the educational institution, influence of its policy on the promotion of educational and social goals, and systems of interaction between teachers and students have been subject to numerous quantitative and qualitative studies. Schools in Israel's Arab sector present a unique challenge to teachers, because the classes often comprise pupils from different backgrounds and lifestyles with varying levels of religious conviction and practice. Beyond teaching the required academic materials, the teachers should find ways to protect and encourage the uniqueness of every group, while fostering unity in the class.

The regular state schools are co-educational institutions, comprising everyone who meet the basic criteria. Thus, 
in schools located in residential areas of mixed population, the student body includes any given class. Private schools can cater to a select group of pupils according to preset criteria, and can design their educational programs to meet the needs and expectations of a specific population. However, state schools do not enjoy such luxury; their criteria of acceptance, facilities, number and size of classes, additional learning space, and administration and staff utilities are determined by the state and, sometimes, local authorities.

As all state schools are co-educational, their programs are designed from a basic view of equality. Their population characteristics depend on location, availability and accessibility of other such institutions in the area, and nature of the population served. Thus, state schools situated in residential areas of similar population have a relatively easier job than those serving a diverse population. Some high schools of the Arabic sector in Galilee serve a relatively similar population, while others have to cope with pupils with diverse cultural characteristics.

In the present study, it was found that schools were not prepared for regrettable events and their implications, and were not engaged in educational programs dedicated to pluralism, tolerance, and respect for others. However, the school leadership and local social and religious heads were noted to be aware of the ensuing problematic situation and willing to cooperate to find the means to rectify it. The prevailing perspective among all educators who participated in this study was that the school should be leading the change required.

\subsection{Conclusions}

The study's results led to the following conclusions.

Educating students in pluralism and tolerance requires several preconditions: the teacher must know the social environment, culture(s) to which the students belong, and mood in relevant social environment.

Development of a tolerant attitude toward different people's opinions and cultural expressions, along with acceptance of their legitimacy, compels educators to examine themselves and guide students to do the same. In other words, constant examination of their own identity will enable pupils to understand and recognize others' right to be different. The acquisition of tolerance and mutual respect will help prepare students to successfully integrate into a multicultural society.

In a state with dominant majority, the minority groups sharing certain cultural characteristics (language, history, and lifestyle aspects) should find ways to overcome differences and emphasize common values to bridge cultural gaps. This strategy benefits all involved, especially when location and linguistic considerations place children of more than one minority group in the same educational system.

The current reality in which local and global societies undergo rapid changes, one of the major roles of all educational systems is to train its graduates to cope with changing situations in an uncertain future. The Arab educational system in Israel serves a society functioning under considerable pressure. Although these schools are designed to serve the minority, they have to adapt to a progressive technological society. Such a case is particularly true when the surrounding society is subject to a social transition process, from the domination of a rural-traditional lifestyle to partial modernization and excessive prevalence of urban and open lifestyle.

The strength and power of every society depend on the quality of its people. The educational system is entrusted with training the young generation to integrate into a society that does not stagnate, and the one that fails to meet the expectations of the society it serves is sentenced to stagnation, as it disconnects itself from reality.

Today, knowledge and information explosion and its availability to students are aspects of the globalization process. The educational system is compelled to adapt itself to function in a different way. In the changing macro-reality, which demands building a long-term educational strategy, policymakers and educational program developers must determine new goals suitable for the future generations and their priorities.

In the micro-reality, there is a need to update the Arab educational system in Israel by fixing operative targets and building an applicable program for their achievement and foundation of a feedback and control system.

Every educational program, especially the one for Israel's Arab sector, should focus on three fields: instilling values, providing skills, and acquiring knowledge.

The first condition for planning a suitable up-to-date system is the presence of an educational leadership with a vision, desire, and willingness to cope with all issues.

An educational leadership is supposed to act on two planes that are intertwined, overlapping, and difficult to separate:

(1) Improving the system's outputs from the perspective of achievements and persistence in learning

(2) Fixing the image of an adult opinion and a system of values, which is supposed to equip him/her. 
In the past, the Arab educational system focused on the first plane and paid less attention to the second. Despite this preference, its outputs showed that the concentration on instrumental achievements failed to bring desired results. According to the researcher, it is an opportune time to consider a revolution in education and emphasize cultural and social values, which could intensify the graduates' personalities and personal and collective identities, challenging them to expand their horizons and encouraging them to invest and excel in academic studies.

\section{Recommendations}

Based on this study's findings, the researcher proposes the following recommendations:

(1) Prepare an intervention program founded on:

- Respect for differences and variety,

- Renunciation of forced uniformity,

- Promotion of maximal freedom in the choice of the mode of life, and

- Dialog among different cultures and identities.

(2) The program should be built in the context of profound and prolonged examination of the sources and causes of tensions among communities, religions, and other subgroups comprising the Arab population in Galilee.

Another recommendation is to form patterns of mutual exposure to cultures, which should be systematic and controlled by stressing and formulating common binding values, considering the well-being of both individual and community to reach cultural and social cohesiveness, while respecting differences and preserving the unique identities of all involved. The program should highlight the meaning of interpersonal connection among students and the school's role in supporting pluralist trends in the society and community.

As an Arab researcher living in Galilee, the researcher perceives change and expansion of horizons as a challenge to both schools and Arab society at large, and hopes that the biographic-narrative platform will trigger a welcome change, at least in those five towns/villages that participated in this study and others that will follow their example.

\section{References}

Agar, M. (1980). The professional stranger: An informal introduction to ethnography. New York, NY: Academic Press.

Arieli, M. (1995). Impatience in teaching. Tel-Aviv: Ramot.

Bodu, P. (1996). The Magdalenian hunters of Pincevent: Aspects of their behavior. Lithic Technology, 21(1), 66-70.

Bostin, A. (2004). To take advantage of the opportunity: The welfare system and immigration absorption. Jerusalem: The Ministry of Welfare, Joint Israel.

Dana, A. (1998). The Druze. Jerusalem: Grafit.

Diab, H. (2002). The missing narrative: Self search. In A. Shai, \& I. Bar-Shalom (Eds.), Qualitative research in education research. Jerusalem: David Yellin College for Education.

Dressel, J. L., Consoli, A. J., Kim, B. S. K., \& Atkinson, D. R. (2007). Successful and unsuccessful multicultural supervisory behaviors: A Delphi poll. Journal of Multicultural Counseling and Development, 35, 51-64. http://dx.doi.org/10.1002/j.2161-1912.2007.tb00049.x

Elbaz-Lobish, P. (2001). Narrative-biographic research in education and teaching. In N. Tzabar-Ben Yehoshua (Ed.), Traditions and currents in qualitative research (pp. 141-165). Lod: Dvir.

El-Haj, M. (1996). Education among the Arabs in Israel-control and change. Jerusalem: Magnes.

Ezer, H., Malat, S., \& Patkin, D. (2004). To hear their voices: The stories of teachers' teachers in a multicultural context. Dapim, 38, 127-151.

Falah, S. (2000). The Druze in the Middle East. Jerusalem: Ministry of Defense Publications.

Ganem, A. (1990). Ideological currents in the question of Jewish-Arab coexistence among the Arabs in Israel in the years 1967-1989 (Essay for a master's degree, Department of Political Sciences, Haifa University, Haifa).

Khamaisi, R. (2011). Arab Society in Israel (4): Population, Society, Economy. Jerusalem: Van leer.

Koboby, D. (1978). In the teacher's to student's eye: The good teacher in the eyes of his students. Tel-Aviv: 
Sifriat Hapoalim \& Hakibbutz Haartzi.

Lam, T. (1996). The idea of pluralism in its applications in education in Israel. In A. Gur-Zeev (Ed.), Education in the era of the post-modernist discourse (pp. 207-220). Jerusalem: Magnes Publications.

Masalha, S. (2004). Individual counseling in a multicultural society. In R. Erhard, \& A. Klingman (Eds.), School counseling in changing society (pp. 229-246). Tel-Aviv: Ramot.

Mautner, M., Sagi, A., \& Shamir, R. (1998). Passing thoughts on multiculturalism in Israel. In M. Mautner, A. Sagi, \& R. Shamir (Eds.), Multiculturalism in a democratic and Jewish state (pp. 67-76). Tel-Aviv: Ramot-Tel-Aviv University.

Mickelson, S. (2001). Approaches to multiculturalism in the world. Gadish, 7, 227-233.

Oppenheimer, E. S. (2006). The roles of the teacher in a heterogeneous class according to the educational approach of Karl Frankenstein. Mifgash leavoda hinukhit-sotzialit (Meeting for educational-social work), $24,107-120$.

Picard, A. (2001). Multiculturalism-the way to a new melting pot. Mifne, 34, 11-17.

Reingold, R. (2005). Curricular models of multicultural pluralist education-four case studies from academia in the United States. Dapim, 40, 108-131.

Saleh, S. (1989). The history of the Druze. Tel-Aviv: Bar Ilan University and the Ministry of Defense.

Saleh, S. (1996). Magar-the anatomy of a mixed village. Kathedra, 81, 75-94.

Sever, R., \& Gur, I. (2001). Contact lenses-intercultural mediation in a youth village full of students of Ethiopian origin. Mifgash leavoda hinukhit-sotzialit, 15, 192-193.

Sever, R. (2001). Assimilating or integrating? A conceptual framework for examination of issues of multiculturalism. Gadish, 7, 45-54.

Shavit, Z. (2002). To return to the cultural core. Panim: Journal for Culture, Society and Education, 20, 113-122.

Shenhav-Keller, S. (2010). From the melting pot to the multicultural society: Three viewpoints on a meeting of cultures in Israel. Mutar, 16-17, 13-17.

Shkedi, A. (2003). Words which try to touch: Qualitative research-theory and application. Tel-Aviv: Tel-Aviv University, Ramot.

Shlaski, S., \& Alpert, B. (2007). Ways for writing qualitative research, from analysis of reality to its structuring as a text. Tel-Aviv: Mofet Institute.

Smooha, S. (1987). Jewish and Arab ethnocentrism in Israel. Ethnic and Racial Studies, 10(1), 1-26. http://dx.doi.org/10.1080/01419870.1987.9993553

Stendal, A. (1992). The Israeli Arabs-between the devil and the deep blue sea. Jerusalem: Akademon.

Suan, D. (2000). A binational society, the Jewish-Arab split in education for tolerance in the State of Israel. Hahinukh vesavivo: Annual of the Kibbutz Seminary, 22, 41-61.

Suwaed, M. (2004). Arabs in Israeli society misgivings of identity. Mifne, 44, 45-59.

Tamir, I. (1998). Two concepts on multiculturalism. In M. Mautner, A. Sagi, \& R. Shamir (Eds.), Multiculturalism in a democratic and Jewish society (pp. 79-92). Tel-Aviv: Ramot Publications.

Tzimhoni, D. (1999). The Christians and Christian communities in Israel today. In Rami Dagani, Churches, communities and Christian orders in Israel. Ariel-Journal for knowledge of the Land of Israel, 137-138, 15-22.

Yaakobson, A. (2012). Zionism in multiculturalism. Mishpat veasakim, 14, 677-721.

Yogev, A. (2001). Approaches to moral education in a pluralistic society. In I. Iram, S. Shkolnikov, I. Cohen, \& A. Schechter (Eds.), Junction: Values in education in Israeli society (pp. 355-379). Jerusalem: The Ministry of Education.

Yona, I., \& Shenhav, I. (2000). The multicultural situation. Teoria vebikoret, 17, 163-188.

Yona, Y. (1998). A state of all its citizens, a nation state or a multicultural democracy? Alpaim, 16, 238-263.

Zolberg, A. R. (1996). Immigration and multiculturalism in the industrial democracies. In R. Baubock, A. Heller, \& R. Zolberg (Eds.), The challenge of diversity: Integration and pluralism in societies of immigration (pp. 
43-66). Wien: European Center for Social Welfare Policy and Research.

\section{Copyrights}

Copyright for this article is retained by the author(s), with first publication rights granted to the journal.

This is an open-access article distributed under the terms and conditions of the Creative Commons Attribution license (http://creativecommons.org/licenses/by/3.0/). 